\title{
Micro and Nanotechnology for Intracellular Delivery Therapy Protein
}

\author{
Dan $\mathrm{Xu}$, Zhenhua Hu, Jing Su, Fei Wu*, Weien Yuan*
}

(Received 1 July 2012; accepted 3 July 2012; published online 7 July 2012)

\begin{abstract}
Proteins therapy is of great importance in the treatment of protein deficiency disease. Most human diseases are related to the malfunctioning of one or more proteins. The most effective and direct approach is protein therapy, which delivers the proteins into the target cell to replace the dysfunction protein and maintain the balance of organism. However, clinical application is frequently hampered by various biological barriers to their successful delivery. This review aims to discuss the recent advances about microparticles and nanoparticles fabricated using micro and nanotechnology for intracellular delivery therapy protein and give some suggestions about the promising delivery system.
\end{abstract}

Keywords: Intracellular delivery; Protein; Nanoparticle

Citation: Dan Xu, Zhenhua Hu, Jing Su, Fei Wu and Weien Yuan, "Micro and Nanotechnology for Intracellular Delivery Therapy Protein", Nano-Micro Lett. 4 (2), 118-123 (2012). http://dx.doi.org/10.3786/nml. v4i2.p118-123

\section{Introduction}

Organisms contain thousands of proteins, which perform a vital role in growth, development, metabolism regulation and disease therapy. These proteins take effect in organism and resist the outside unfavorable factors. Therefore, those specific proteins have shown to be a suitable target for drug research and development $(R \& D)$. The Pharmaceutical Research and Manufacturers of America's (PhRMA) listed 66 protein drugs in 633 new biotechnology medicines relating to more than 100 diseases in 2008, including virus infectious, cancer and autoimmune diseases [1]. The drug target for chemical compounds is not currently certain and the non-specific interaction between the compounds and unexpected proteins may cause intense side-effects on patients in clinical trials. Hence, protein therapy is considered as the most effective and direct approach for the dysfunctional protein disease.

Protein drugs gradually become the major in future and thus play a critical role in the process of modern drug design. Although it has a broad application prospect, the protein therapeutic potential and clinical application is frequently hampered by various biological barriers [2].

In contrast to injecting to human body directly, the protein drug must overcome several biological barriers. For example, protein delivery in the bloodstream need avoiding kidney filtration, uptake by phagocytes, aggregation with serum proteins, and degradation by endogenous nucleases [3]. In the bloodstream, phagocytes cells such as monocytes and macrophages remove foreign material from the body to protect against infection by fungi, bacteria and also certain therapeutic protein complexes. Also, it is another challenge that protein drug need get through the bloodstream and the vascular endothelial barriers. Protein drugs can not be allowed the entry the certain tissues including the liver, spleens, and some tumors until they are cleared from the body [4]. Moreover, having been taken up by the target cell, protein drugs must escape from the endosome to cytoplasm immediately in case they may degrade in decreasing $\mathrm{pH}$ and various hydrolytic enzymes from lysosome [5]. Finally, protein must be released 
from the carrier if formulated with delivery agents.

In order to effective protein therapy, we need an effective delivery system to deliver the protein. And the future delivery system must be safer and can also take account of the barriers in organism. For these reasons above, this review aims to present on-going research on protein drug delivery system and serve to update readers regarding new developments in protein delivery systems while proving suggestions for future advancements.

\section{Drug delivery systems}

\section{Single-protein}

Although most studies use biocompatible materials to delivery the protein drugs, some researches reported systemic delivery vehicles containing cell-penetration peptides (CPPs) liked to the target protein for effective transduction. The transactivator of transcription (TAT) was a prototypical example of a cell-penetrating peptide. In 1988, Frankel and Pabo [6] and Green and Lowenstein [7] independently discovered that the transactivator of transcription (TAT) protein separated from the Human Immunodeficiency Virus can penetrate cells and activate the viral genome replication. The protein modified by TAT peptide can enter cells efficiently while non-conjugated proteins were notable in the incubation media rather than in cells [8]. Sun et al (2009) has fused apoptin (a tumor specific killing protein) to the transduction domain named protein transduction domain 4 (PTD4), which is 11-amino acid sequence. It has shown to delivery proteins across the cellular membrane in a very efficient way [9]. The data showed that PTD4-apoptin protein was delivered across cellular membranes and the fused apoptin protein can significantly inhibited tumor growth in vivo [10].

The cell-penetration peptides can also help fusion protein enter into the target cell, mainly due to the specific electrostatic interaction and confirmation. The specific amino acid residues of cell-penetration peptide may interact with the plasma membranes by strongly electric complementation. Substitution of any basic residue of TAT with neutral amino acid may restrain the interaction with membranes, implying the charge of TAT is necessary for cellular uptake [11]. Furthermore, the specific binding receptor on the surface of target cells can also induce membrane deformation for cellular delivery [12].

However, protein native confirmation may change in the process of protein modified and intracorporeal circulation, which may induce the non-specific immunity. So the stability, side effect and nonspecific immunogenicity need to be taken into account for fusion protein therapeutic treatment of human disease.

\section{Micropaticles}

Generally, micropaticles are defined as particles between 1 and $1000 \mu \mathrm{m}$. Microparticle vesicles have studies extensively with many different materials and polymers since first designed in the early seventies. These different formulations of micropaticles can resist degrading by enzyme and prolong protein's life in vivo. The following examples present various micropaticles designed for protecting the protein drug.

Ploy (lactic-co-glcolic acid) (PLGA) can provided sustained delivery of active VGEF (vascular endothelial growth factor) in vivo for more than a month after transplant [13]. One month after treatment an increase in angiogenesis (small caliber caveolin-1 positive vessels) and arteriogenesis ( $\alpha$-SMA-positive vessels) was observed in animals treated with VEGF microparticles, but not in free-VEGF groups. It has demonstrated that the use of microparticles can protect the activity of protein that can be easily and safely deliver to targets. Furthermore, other researchers pay more focus on the sustained-release of micropaticles, because sustained-release technology can reduce dosing frequency, maximizing the efficacy and reduce poor patient compliance [14]. Using the 10\% PEG with PLGA microparticles (MP), $45 \%$ of loading BSA was continuously released during 4 week [15]. Similarly, a new sustained-release amylopectin microsphere coated with polylactide-coglycolide can maintain the human growth hormone $(\mathrm{hGH})$ above the baseline for at least 14 days [16]. The data suggest longer-term trials in adults with injection frequencies of no more than once every 2-3 weeks. Moreover, for tissue regeneration therapy, the sustained-release microparticles can preciously regulate the stem cell growth and development. Microparticles, within aggregates of pluripotent stem cell (PSCs), can stably control the spatial differentiation of stem cell [17]. In general, these above strategies of microparticles proved to be of considerable potential values to clinical use.

Unfortunately, although sustained-release micropaticles can reduce the dosing frequency and increasing patient compliance, there are very few microparticle delivery formulations approved for clinical use [18]. Several problems such as initial burst release and denaturation of entrapped proteins have prevented the realization of commercially viable products. The microparticles utilize various emulsions in formation processes. Protein may happen to denature after contacting the water/oil interface. So the mostly important issue is that the materials of microparticles need to easily incorpotate with protein and maintain the native the conformation both in preparation and in preserve.

Our lab has invented aqueous-aqueous emulsion formed to encapsulate proteins into dextran microparticles [19-21] and further encapsulated into PLGA mi- 
croparticles [21]. Erythropoietin (EPO) is a recombinant protein drug which is used to treat aplastic anemia. But EPO in vivo were likely to aggregate and cause the protein denaturation, which may increase heart problems and even increase mortality in chronic kidney disease patients [22]. But our aqueous-aqueous emulsion can provide friendly environment for protein drug because protein can not contact the hydrophobic interface. The result showed EPO can release from the composite PLGA microspheres with normal biological activity without significant aggregation $(<2 \%)$. Meanwhile, the near zero-order release without a significant initial burst $(<20 \%$ at the first day) was achieved using our aqueous-aqueous emulsion.

Looking at the various formulation materials and preparation methods, the design of microparticle DDSs should be considered compatibility with the protein drug as well as the host. To reduce negative side-effects and unwarranted interaction with the host, researchers should also opt for safer materials that can not influence the protein structure, stability and other properties. However, largely-sized microparticles can not be allowed the entry the target cell and also encounter other barriers such as the blood-brain barrier. Thus, nanoparticles might appear to overcome the biological barriers.

\section{Nanoparticles}

Nanoparticle(NP) is a rapidly expanding area, including the development of materials in the 5 to 1000 $\mathrm{nm}$ size range. The protein is entrapped, encapsulated in the NP depending upon the method of preparation. Owing to submicron in size, NPs are small enough to avoid reticuloendothelial and phagocytic clearance. So they can penetrate deep into tissues through fine capillaries and are easily taken up efficiently by the target cells [23]. Also they can overcome the barriers and have excellent biocompatibility in contrast to larger microparticles.

This review focuses on intracellular delivery of therapeutic agents, so we compare various types of nanoparticles, which have merits and demerits respectively (Ta- ble 1). The main reason of demerit is that these formulations do not overcome our biologic barriers totally. The nanoparticles should be designed not only for protein entrapment, but also for good therapeutic effect. So it is extremely necessary to understand more mechanisms of intracellular delivery before designing. Figure 1 shows the steps detailing the endocytosis mechanism. Following their uptake, nanoparticles begin intracellular trafficking. Firstly they are transported to endosomes, which fuse with lysosomes subsequently. After that, nanoparticles release from lysosomes into the cytoplasm, and diffuse to the therapeutic target, such as nucleus and other organelles. In the whole process, the biggest challenge is how nanoparticles escape the endolysomes and enter the cytoplasm. Varkouli reviewed advanced mechanisms of endosomal escape, which included pore formation in the endosomal membrane, $\mathrm{pH}$ buffering effect (the proton sponge effect).

'Proton- sponge' is now the most accepted mechanisms [29]. Taking full advantage of the low $\mathrm{pH}$ range ( $\mathrm{pH}$ 4.6-5.0) in endo-lysosomes, many groups focuses on synthetic $\mathrm{pH}$-responsive polymer for protein transduction [30]. Endo-lysosomes are acidified by the ATPase enzymes on the surface that transport protons and counter ions from the cytoplasm into the endolysosomes. The synthetic $\mathrm{pH}$-responsive polymer can combine the protons to prevent acidification, causing the ATPase continuing to transport more protons to reach the desired $\mathrm{pH}$. The accumulations of osmotic pressure by counter ions ultimately trigger swelling and rupture the endosome membrane, while releases the polymer loading protein at the same time [31]. Yan and his colleague report a novel delivery polymer that consists of the neutral monomer (acrylamid) and degradable crosslinker (acid-degradable glycerol dimethacrylate) [32]. The endosomes staining of the cells incubated with rhodamine-B-labelled horseradish peroxidase (HRP) revealed co-localization of the protein with early endosomes, with gradual escaping from endolysosome to the cytoplasm. Moreover, the released proteins can also execute their own function in cytosol including enhanced green fluorescent protein (EGFP), sueroxide dismutase (SOD) and caspase-3 (CAS).

Table 1 Comparation of various types of therapeutic agents for intracellular delivery

\begin{tabular}{llll}
\hline $\begin{array}{c}\text { Therapeutic } \\
\text { agent }\end{array}$ & advantage & Disadvantage & Reference \\
\hline $\begin{array}{l}\text { Polymeric } \\
\text { Nanoparticle }\end{array}$ & $\begin{array}{l}\text { Surface modification provide a wide range of } \\
\text { therapeutic agents }\end{array}$ & Large scale & \\
Inorganic & Stable over broad range of temperature and pH & Lack of biodegradation & Slow dissolution \\
Nanoparticle & & Unstable and low entrapment efficiency & {$[23][24]$} \\
Liposome & A good biocompatibility & Debatable toxicity & {$[25][26]$} \\
Nanotube & Large internal volumes for drug & Cytotoxicity, biocompatibility and biodistribution & {$[28]$} \\
Dendrimer & Ease of modification and size control & [27] & \\
\hline
\end{tabular}




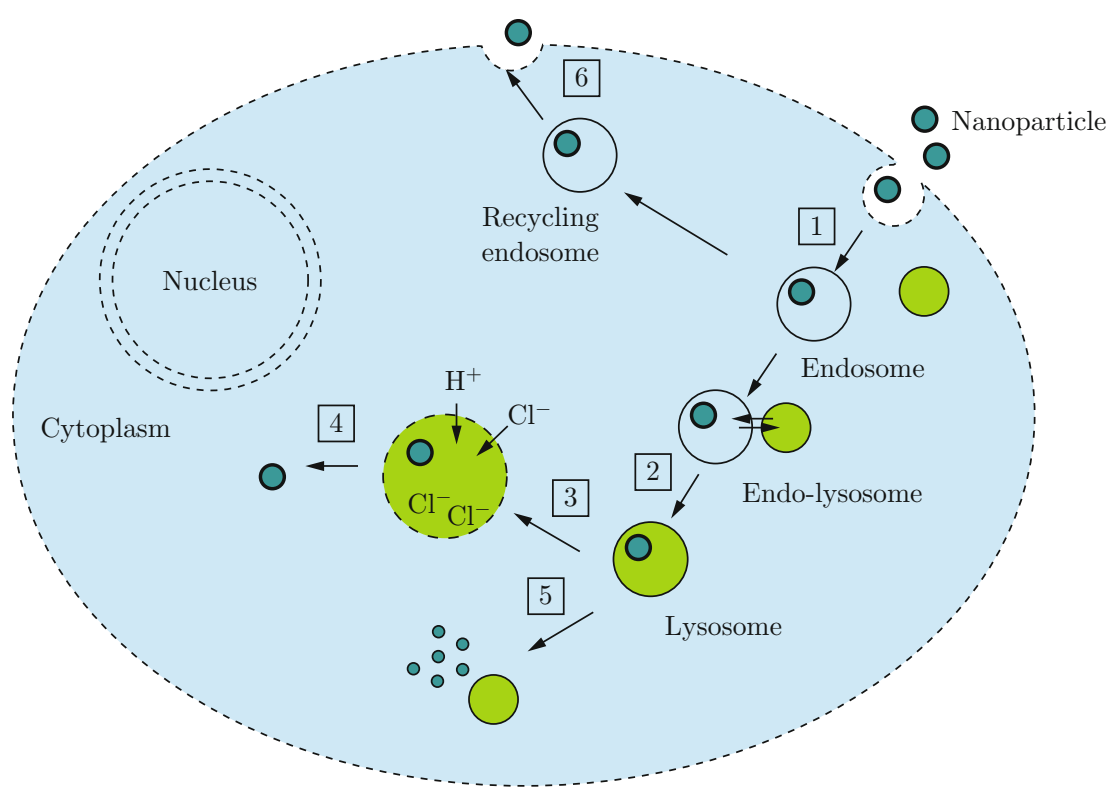

Fig. 1 Steps detailing the intracellular delivery of protein drug via nanoparticle carriers. (1) endocytosis of nanoparticles; (2) fusion of endosomes with lysosomes; (3) 'proton-sponge' effect; (4) endosomal escape of nanoparticles; (5) degradation of nanoparticle by lysosome; (6) exocytosis of nanoparticles.

Another mechanism of escaping from endo-lysosomes is causing damage and fracture of the endosome membrane. Amphiphilic polymers containing weakly ionizable carboxyl groups and hydrophobic alkyl side chains may response to acid environment and degrade below their $\mathrm{p} K_{\mathrm{a}}$ ranges [33]. The degraded hydrophobic fragment can bind to endosomal membrane because the inner of membrane is hydrophobic fatty acid. Then the additional hydrophobic fragment can interrupt the membrane fluidity, subsequently inducing membrane lysis activity [34]. Liechty et al confirmed the phenylalanine derivatized polymer PP-75 have the ability of endosomal membrane disruption $[35,36]$. After treatment of Saos-2 cells with MBP-apoptin (a specific tumor killing protein) and PP-75, 30\% cells found in the mid-apoptotic state compared with control. This result showed the protein can release successfully from the endo-lysosomes by the destructive hydrophobic polymer $[37,38]$.

Apart from endocytosis, nanoparticles should also meet the various demand of organism in biocompatibility and biodistribution. The barriers should be taken into account seriously for designing a more effective formulation.

\section{Future directions}

With the rapid development of molecular biology, more and more are being understood about various proteins and their roles in regulatory networks of human health and disease. Unfortunately, delivery approach remains to be the most significant barrier of widespread use in clinic of protein therapeutics. There is still a lack of good micro- and nano-delivery systems fabricated using micro and nanotechnology for protein available which can overcome all the biological barriers. From discussion above, the on-going research must consider the following: (1) low toxicity of material; (2) nonspecific activation of the immune system; (3) encapsulation efficiency; (4) maintaining the nature confirmation; (5) sustained-release instead of burst release effect; (6) target the diseased tissues or cells; (7) biodegradability; (8) controlled, sustained release of therapeutics. So the future work need focus on develop the safe and effective delivery system to ensure the broadest application of protein therapy in the clinic.

\section{Acknowledgments}

This work was partially supported by the program of Major scientific and technological specialized project for "significant new formulation of new drugs" (No. 2009ZX09310-007 and No. 2009ZX09301007), National Science Foundation of China Committee (No. 30873180), Ph.D. Programs Foundation of Ministry of Education of China (No. 20090073120085), and the Shanghai Science and Technology Committee (No. 0952nm03700 and No. 0952nm03700). The authors thank the Analytical Center of Shanghai JiaoTong University for Technical Support. 


\section{References}

[1] R. Q. Wan, E. C. Noguera and S. R. B. Weis, Neuro. Report. 9, 677-682 (1998). http://dx.doi.org/10. 1097/00001756-199803090-00021

[2] W. Wang, Int. J. Pharm. 185, 129 (1999). http://dx. doi .org/10.1016/S0378-5173(99)00152-0

[3] F. Alexis, E. Pridgen, L. K. Molnar and O. C. Farokhzad, Mol. Pharm. 5, 505 (2008). http://dx. doi.org/10.1021/mp800051m

[4] J. Zámečnik, L. Vargová, A. Homola, R. Kodet and E. Syková, Neuropath. Appl. Neuro. 30, 338 (2004). http://dx.doi.org/10.1046/j.0305-1846. 2003.00541.x

[5] G. M. D. Guglielmo, C. L. Roy, A. F. Goodfellow and J. L. Wrana, Nat. Cell Biol. 5, 410 (2003). http://dx . doi.org/10.1038/ncb975

[6] A. D. Frankel and C. O. Pabo, Cell, 55, 1189 (1998). http://dx.doi.org/10.1016/ 0092-8674 (88) 90263-2

[7] Green, M. Loewenstein and P.M., Cell 55, 1179 (1998). http://dx.doi.org/10.1016/ 0092-8674 (88) 90262-0

[8] V. Torchilin, R. Rammohan, V. Weissig and T. Levchenko, Proc. Natl. Acad. Sci. 98, 8786 (2001). http://dx.doi.org/10.1073/pnas. 151247498

[9] A. Ho, S. R. Schwarze, S. J. Mermelstein, G. Waksman and S. F. Dowdy, Cancer Res. 61, 474 (2001).

[10] J. Sun, Y. Yan, X. T. Wang, X. W. Liu, D. J. Peng, M. Wang, J. Tian, Y. Q. Zong, Y. H. Zhang, M. H. M. Notebornand S. Qu, Int. J. Cancer 124, 2973 (2009). http://dx.doi.org/10.1002/ijc. 24279

[11] A. Ziegler, X. Blatter, A. Seelig and J. Seelig, Biochemistry 42, 9185 (2003). http://dx.doi.org/10.1021/ bi0346805

[12] B. Guelen, H. Paterson, J. Gaken, M. Meyers, F.Farzaneh and M. Tavassoli, Oncogene 23, 1153 (2004). http://dx.doi.org/10.1038/sj.onc. 1207224

[13] F. R. Formiga, B. Pelacho, E. Garbayo, G. Abizanda, J. J. Gavira, T. Simon-Yarza, M. Mazo, E. Tamayo, C. Jauquicoa, C. Ortiz-de-Solorzano, F. Prósper, and M. J. Blanco-Prieto, J. Control. Release 147, 30 (2010). http://dx.doi.org/10.1016/j.jconrel. 2010.07.097

[14] S. Marc, S. Juergen, W. E. Hennink, J. Wim, J. Control. Release. 119, 301 (2007). http://dx. doi.org/10. $1016 / j \cdot j$ conrel . 2007.03.003

[15] W. Jiang and S. P. Schwendeman, Pharm. Res. 18, 878 (2001). http://dx.doi.org/10.1023/A: 1011009117586

[16] A. Jostel, A. Mukherjee, J. Alenfall, L. Smethurst and S. M. Shalet, Clin. Endocrinol. 62, 623 (2007). http: // dx.doi.org/10.1111/j.1365-2265.2005.02271.x

[17] A. M. Bratt-Leal, R. L. Carpenedo, M. D. Ungrin, P. W. Zandstra and T. C. McDevitt, Biomaterials 32, 48 (2011). http://dx.doi.org/10.1016/j. biomaterials. 2010.08.113
[18] M. L. Tan, P. F. M. Choong, C. R. Dass, Peptides 31, 184 (2010). http://dx.doi.org/10.1016/j. peptides.2009.10.002

[19] W. Yuan, Y. Geng, F. Wu, Y. Liu, M. Guo, H. Zhao and T. Jin, Int. J. Pharm. 366, 154 (2009). http:// dx.doi.org/10.1016/j.ijpharm. 2008.09.007

[20] W. Yuan, F. Wu and T. Jin, Polym. Adv. Technol. 20, 834 (2009). http://dx.doi.org/10.1002/pat. 1338

[21] Y. Geng, W. Yuan, F. Wu, J. Chen, M. He and Y. Jin, J. Control. Release 130, 259 (2008). http://dx.doi. org/10.1016/j.jconrel.2008.06.011

[22] T. B. Drueke, F. Locatelli, N. Clyne, K. U. Eckardt, I. C. Macdougal, D. Tsakiris, H. U. Burger and A. Scherhag, New Eng. J. Med. 355, 2071 (2006). http://dx. doi.org/10.1056/NEJMoa062276

[23] S. V. Vinogradov, T. K. Bronich and A. V. Kabanov, Adv. Drug Deliv. Rev. 54, 135 (2002). http://dx.doi. org/10.1016/S0169-409X (01) 00245-9

[24] A. K. Varkouhi, M. Scholte, S. Gert and J. H. Hidde, J. Control. Release (2011). http://dx.doi.org/10. 1016/j j jconrel. 2010.11.004

[25] P. Calvo, B. Gouritin, H. Chacun, D. Desmaile, J. D’Angelo, J. P. Noel, D. Georgin, E. Fattal, J. P. Andreux and P. Couvreur, Pharm. Res. 18, 157 (2001). http://dx.doi.org/10.1023/A: 1010931127745

[26] N. E. Botterhuis, Q. Sun, P. C. M. M. Magusin, R. A. Van Santen and N. A. J. M. Sommerdijk, ChemEur. J. 12, 1448 (2006). http://dx.doi.org/10.1002/ chem. 200500588

[27] C. Y. Lai, B. G. Trewyn, D. M. Jeftinija, K. Jeftinija, S. Xu, S. Jeftinija and V. S. Y. Lin, J. Am. Chem. Soc. 125, 4451 (2003). http://dx.doi.org/10.1021/ ja0286501

[28] G. Weissmann and G. Sessa, J. Lipid Res. 9, 310 (1968).

[29] C. R. Dass, T. L. Walker, M. A. Burton, J. Pharm. Pharmacol. 49, 972 (1997). http://dx.doi.org/10. 1111/j.2042-7158.1997.tb06025.x

[30] A. E. Porter, M. Gass, K. Muller, J. N. Skepper, P. A. Midgley, M. Welland, Nat. Nanotechnol. 2, 713 (2007). http://dx.doi.org/10.1038/nnano.2007.347

[31] C. C. Lee, J. A. MacKay, J. M. J. Fréchet and F. C. Szoka, Nat. Biotechnol. 23, 1517 (2005). http://dx. doi.org/10.1038/nbt1171

[32] D. W. Pack, A. S. Hoffman, S. Pun and P. S. Stayton, Nat. Rev. Drug. Discov. 4, 581 (2005). http:// dx.doi.org/10.1038/nrd1775

[33] O. Boussif, H. F. LezoualC, M. A. Zanta, M. D. Mergny, D. Scherman, B. Demeneix and J. P. Behr, Proc. Natl. Acad. Sci. USA 92, 7297 (1995). http:// dx. doi.org/10.1073/pnas.92.16.7297

[34] N. D. Sonawan, R. C. Szoka and A. S. Verkman, J. Biol. Chem. 278, 44826 (2003). http://dx.doi.org/ 10. $1074 /$ jbc. M308643200

[35] M. Yan, J. Du, Z. Gu, M. Liang, Y. Hu, W. Zhang, S. Priceman, L. Wu, Z. H. Zhou, Z. Liu, T. Segura, Y. Tang and Y. Lu, Nat. Nano. 5, 48 (2010). http://dx. doi.org/10.1038/nnano.2009.341 
[36] M. A. Yessine, M. Lafleur, C. Meier, H. U. Petereit and J. C. Leroux, BBA - Biomembranes, 1613, 28 (2003).

[37] C. Kusonwiriyawong, P. V. D. Wetering, J. A. Hubbell, H. P. Merkle and E. Walter, Euro. J. Pharm. Biopharm. 56, 237 (2003). http://dx.doi.org/10.1016/
S0939-6411 (03) 00093-6

[38] W. B. Liechtyi, R. Chen, F. Farzaneh, M. Tavassoli and N. K. H. Slater, Adv. Mater. 21, 3910 (2009). http://dx.doi.org/10.1002/adma. 200901733 